\title{
PENGARUH MODEL PEMBELAJARAN SCIENTIFIC INQUIRY TERHADAP HASIL BELAJAR SISWA PADA MATERI FLUIDA DINAMIS KELAS XI SEMESTER II DI SMA NEGERI 1 PANCUR BATU TAHUN PELAJARAN 2015/2016
}

\author{
Yunianti Pratiwi dan Motlan \\ Jurusan Fisika FMIPA Universitas Negeri Medan \\ Jalan Willem Iskandar Pasar V Medan, Sumatera Utara \\ pratiwiyunianti5@gmail.com
}

\begin{abstract}
ABSTRAK
Penelitian ini bertujuan untuk mengetahui pengaruh hasil model pembelajaran scientific inquiry terhadap hasil belajar siswa pada materi fluida dinamis kelas XI semester II di SMA Negeri 1 Pancurbatu Tahun Pelajaran 2015/2016. Jenis penelitian ini adalah quasi experiment dengan desain two group pretest posttest. Pengambilan sampel dilakukan dengan cara cluster random sampling. Sampel untuk kelas eksperimen dan kelas kontrol masing-masing berjumlah 30 siswa dengan kelas XI IPA 1 sebagai kelas eksperimen menggunakan model scientific inquiry dan kelas XI IPA 3 sebagai kelas kontrol menggunakan pembelajaran konvensional. Berdasarkan analisis data dan pembahasan hasil pengujian hipotesis bahwa ada pengaruh yang signifikan dalam penggunaan model pembelajaran scientific inquiry terhadap hasil belajar yang diperoleh siswa pada materi fluida dinamis kelas XI semester II di SMA Negeri 1 Pancurbatu $\left(t_{\text {hitung }}=6,5>t_{\text {tabel }}\right)$
\end{abstract}

Kata kunci: model scientific inquiry, fluida dinamis, hasil belajar.

\begin{abstract}
This research aims to determine the effects of the use os scientific inquiry model of teaching on students achievement on dynamic fluids topic of second year Senior High School (SMA Negeri 1 Pancurbatu) of academic year 2015/2016. This research was quasi experiment with design two group pretest posttest. Samples was chosed by random sampling method. Samples for both experiment and controled classes were each of 30 students with XI IPA 1 for experimental used scientific inquiry learning model and XI IPA 3 for control used conventional learning model. Based on data and statistic analysis it was found that the use of scientific inquiry model gives significant improvement compared to conventional strategy on students achievement on dynamic fluids topic of second year SMA Negeri 1 Pancurbatu ( $\left.t_{\text {value }}=6,5>t_{\text {table }}\right)$.
\end{abstract}

Keyword: scientific inquiry learning model, dynamic fluids, learning achievement 


\section{PENDAHULUAN}

Kualitas pendidikan di suatu negara menentukan keberhasilan bagi peserta didik. Hasil belajar yang memuaskan ditentukan oleh kualitas guru, minat belajar peserta didik dan sarana pendukung proses pembelajaran. Pembelajaran fisika sekarang ini lebih didominasi oleh guru. Guru biasanya menggunakan pembelajaran konvensional dan lebih terfokus pada rumus-rumus yang ditulis di papan dan tidak mampu mengaplikasikan ke dalam kehidupan sehari-hari. Sehingga siswa kurang kesempatan untuk mempelajari, mengamati dan menemukan secara mandiri.

Berdasarkan hasil wawancara dengan salah satu guru fisika di SMA Negeri 1 Pancurbatu menyatakan bahwa $60 \%$ dari 30 siswa yang tidak mampu mencapai nilai sesuai kriteria ketuntasan minimal (KKM) yaitu 75. Rendahnya hasil belajar ini dikarenakan guru masih menggunakan pembelajaran konvensional dengan metode ceramah.

Guru juga jarang melakukan percobaan pada pembelajaran dikarenakan alat praktikum yang kurang lengkap. Faktanya siswa sangat menginginkan pembelajaran dengan melakukan percobaan dan diskusi kelompok. Hal ini sesuai dengan hasil data pada angket yaitu $83 \%$ dari 30 siswa menginginkan pembelajaran dengan melakukan percobaan. Penggunaan model yang kurang bervariasi oleh guru membuat siswa menjadi kurang aktif selama pembelajaran.

Model pembelajaran (Joyce et all, 2009) adalah suatu pola atau rencana yang sudah direncanakan sedemkian rupa dan digunakan untuk menyusun kurikulum, mengatur materi pelajaran dan memberi petunjuk kepada pengajar di kelasnya. Penggunaan model pembelajaran yang inovatif dapat membuat pembelajaran fisika menjadi menyenangkan. Salah satu model pembelajaran tersebut adalah model pembelajaran scientific inquiry. Model ini dapat digunakan untuk meningkatkan hasil belajar siswa khususnya pada pelajaran fisika.
Pembelajaran dengan scientific inquiry sesuai dengan standar kompetensi kelulusan pada kurikulum tingkat satuan pendidikan (KTSP) SMA bidang studi fisika, dimana mengharuskan peserta didik SMA agar dapat melakukan percobaan, antara lain merumuskan masalah, mengajukan danmenguji hipotesis, menentukan variabel, merancang dan merakit instrumen,mengumpulkan, mengolah dan menafsirkan data, menarik kesimpulan, serta mengkomunikasikan hasil percobaan secara lisan dan tertulis (Badan Standar Nasional, 2006).

Schwab (dalam Sihotang, 2014) mengemukakan bahwa model pembelajaran scientific inquiry dirancang untuk pembelajaran sistem penelitian dari suatu disiplin dan juga memiliki efek dalam domain lainnya; metode sosial dapat diajarkan untuk meningkatkan pemahaman sosial dan pemecahan masalah sosial. Model pembelajaran scientific inquiry, siswa dibimbing oleh guru dalam memahami konsep melalui serangkaian percobaan.

Sintaks dalam model pembelajaran scientific inquiry ini terdiri dari 4 tahap. Tahap pertama, siswa disajikan bidang penelitian, yang meliputi metodologimetodologi yang digunakan dalam penelitian tersebut. Tahap kedua, masalah mulai disusun sehingga siswa dapat mengidentifikasi masalah dalam penelitian tersebut. Tahap ketiga, siswa diminta untuk berspekulasi tentang masalah tersebut, sehingga dia dapat mengidentifikasi kesulitan yang dilibatkan dalam penelitian. Tahap keempat, siswa diminta untuk berspekulasi tentang cara-cara memperjelas kesulitan tersebut, dengan merancang kembali uji coba, mengolah data dengan cara yang berbeda, menghasilkan data, mengembangkan konstruk-konstruk, dan sebagainya (Joyce et all, 2009).

Salah satu peneliti yang menerapkan model scientific inquiry adalah Rahayu (2015) di SMPN 1 Adimulyo Kebumen. Hasil penelitiannya menunjukkan bahwa ada peningkatan hasil belajar kognitif 
sebesar 30,41\% dari 32 siswa dan hasil belajar afektif sebesar $23,11 \%$ dari 32 siswa.

Berdasarkan masalah di atas, maka penelitian ini bertujuan untuk mengetahui pengaruh hasil model pembelajaran scientific inquiry terhadap hasil belajar siswa pada materi fluida dinamis kelas XI semester II di SMA Negeri 1 Pancurbatu Tahun Pelajaran 2015/2016.

\section{METODE PENELITIAN}

Penelitian ini telah dilaksanakan di SMA Negeri 1 Pancurbatu. Waktu penelitian ini dimulai pada bulan Maret 2016 sampai bulan April 2016 pada tahun pelajaran 2015/2016. Populasi dalam penelitian ini adalah semua siswa-siswi kelas XI SMA Negeri 1 Pancurbatu pada semester genap tahun pelajaran 2015/2016 yang terdiri dari 5 kelas yaitu kelas XI IPA 1 sampai kelas XI IPA 5. Sampel penelitian terdiri atas dua kelas yang mewakili populasi dengan mempunyai karakteristik yang sama. Pengambilan sampel menggunakan cluster random sampling. Salah satu kelas sebagai kelas eksperimen yang diajarkan dengan menggunakan model pembelajaran scientific inquiry yaitu kelas XI IPA 1 dan kelas kontrol yang diajarkan dengan menggunakan model pembelajaran konvensional yaitu kelas XI IPA 3 yang masing-masing kelas berjumlah 30 orang.

Jenis penelitian adalah quasi experiment (eksperimen semu). Penelitian ini dimaksudkan untuk mengetahui ada atau tidaknya pengaruh model pembelajaran scientific inquiry terhadap hasil belajar siswa. Desain penelitian yang digunakan adalah two group pretest-posttest seperti ditunjukkan pada Tabel 1. Penelitian ini melibatkan dua kelas yang diberi perlakuan yang berbeda. Untuk mengetahui hasil belajar fisika siswa yang diperoleh dengan penerapan dua perlakuan tersebut pada siswa diberi tes. Tes yang diberikan yaitu pretest sebelum perlakuan dan posttest setelah perlakuan.

Tabel 1 Desain Penelitian

\begin{tabular}{|l|l|l}
\hline Sampel & Pre- & Perlakuan \\
\hline
\end{tabular}

\begin{tabular}{|l|l|l|l|}
\hline & test & & test \\
\hline Eksperimen & $\mathrm{T}_{1}$ & $\mathrm{X}_{1}$ & $\mathrm{~T}_{2}$ \\
\hline Kontrol & $\mathrm{T}_{1}$ & $\mathrm{X}_{2}$ & $\mathrm{~T}_{2}$ \\
\hline
\end{tabular}

Keterangan:

$$
\begin{array}{ll}
\mathrm{T}_{1} & \text { : Pretest } \\
\mathrm{T}_{2} & \text { : Posttest } \\
\mathrm{X}_{1} & \text { : Pembelajaran scientific } \\
& \text { inquiry } \\
\mathrm{X}_{2} & \text { : Pembelajaran konvensional }
\end{array}
$$

Instrumen yang digunakan untuk mengumpulkan data hasil belajar siswa adalah tes hasil belajar siswa pada pokok bahasan fluida dinamis, yang terdiri 20 soal dalam bentuk pilihan ganda dengan lima opsi (a, b, c, d, dan e). Tes dilakukan sebanyak 2 kali yaitu tes awal (pretest) dan tes akhir (post-test).

Instrumen untuk mengetahui aktivitas siswa selama pembelajaran dilakukan sesuai dengan sintaks yang dilaksanakan selama pembelajaran yaitu pada kelas eksperimen dengan sintaks model pembelajaran scientific inquiry dan pada kelas kontrol dengan sintaks model konvensional.

Sebagai analisis data, dilakukan uji prasyarat data. Uji prasyarat data dilakukan dengan uji normalitas dan uji homogenitas. Uji hipotesis penelitian dilakukan dengan uji t. Penilaian pretest dilakukan uji hipotesis dua pihak menggunakan uji t. Uji hipotesis dua pihak menggunakan uji $t$ untuk mengetahui kesamaan kemampuan awal siswa pada kelompok sampel Sudjana, (2001).

Penilaian posttest dilakukan uji hipotesis satu pihak menggunakan uji t. Uji hipotesis satu pihak menggunakan uji $t$ untuk mengetahui pengaruh dari suatu perlakuan, yaitu model pembelajaran scientific inquiry terhadap hasil belajar siswa.

\section{HASIL DAN PEMBAHASAN Hasil Penelitian}

Kedua kelas sampel, diberikan pretest dengan tujuan untuk mengetahui kemampuan awal dari siswa. Berdasarkan data hasil penelitian diperoleh nilai rata-rata 
pretest pada kelas eksperimen sebesar 31,5 dengan standar deviasi sebesar 10,6 dan kelas kontrol sebesar 30,3 dengan standar deviasi sebesar 10. Hasil ditunjukkan pada Tabel 2.

Tabel 2 Hasil Pretest Kelas Eksperimen dan Kelas Kontrol

\begin{tabular}{|c|c|c|c|c|}
\hline \multirow[t]{2}{*}{ Nilai } & \multicolumn{2}{|c|}{ Eksperimen } & \multicolumn{2}{|c|}{ Kontrol } \\
\hline & $\mathbf{F}$ & $\begin{array}{l}\text { Rata- } \\
\text { rata }\end{array}$ & $\mathbf{F}$ & $\begin{array}{l}\text { Rata- } \\
\text { rata }\end{array}$ \\
\hline 10 & 1 & \multirow{10}{*}{31,5} & 2 & \multirow{10}{*}{30,3} \\
\hline 15 & 3 & & 2 & \\
\hline 20 & 2 & & 3 & \\
\hline 25 & 4 & & 3 & \\
\hline 30 & 5 & & 5 & \\
\hline 35 & 7 & & 8 & \\
\hline 40 & 3 & & 4 & \\
\hline 45 & 3 & & 3 & \\
\hline 50 & 2 & & & \\
\hline Jumlah & 30 & & 30 & \\
\hline
\end{tabular}

Hasil pretest kedua kelas juga ditunjukkan pada Gambar 1.

Gambar 1 Diagram Batang Data Pretest Kelas Eksperimen dan Kelas Kontrol

Setelah diberikan pretest, maka kedua sampel diberikan posttest. Hasil Posttest dapat ditunjukkan pada Tabel 3.

Tabel 3 Hasil Posttest Kelas Eksperimen dan Kelas Kontrol

\begin{tabular}{|l|l|l|}
\hline Nilai & Eksperimen & Kontrol \\
\hline
\end{tabular}

\begin{tabular}{|c|c|c|c|c|}
\hline & $\mathbf{F}$ & $\begin{array}{l}\text { Rata- } \\
\text { rata }\end{array}$ & $\mathbf{F}$ & $\begin{array}{l}\text { Rata- } \\
\text { rata }\end{array}$ \\
\hline 60 & 2 & \multirow{8}{*}{76,3} & 5 & \multirow{8}{*}{63} \\
\hline 65 & 3 & & 10 & \\
\hline 70 & 5 & & 8 & \\
\hline 75 & 7 & & 3 & \\
\hline 80 & 4 & & 2 & \\
\hline 85 & 6 & & 2 & \\
\hline 90 & 3 & & & \\
\hline Jumlah & 30 & & 30 & \\
\hline
\end{tabular}

Hasil posttest kedua kelas juga ditunjukkan pada Gambar 2.

Gambar 2 Diagram Batang Data Posttest Kelas Eksperimen dan Kelas Kontrol

Hasil uji normalitas dan uji homogenitas diperoleh bahwa kedua data pretest dan posttest pada kelas eksperimen dan kelas kontrol diperoleh data yang normal dan homogen.

Hasil uji hipotesis dua pihak menggunakan uji t diperoleh bahwa $\mathrm{t}_{\text {hitung }}$ 0,44 dan $t_{\text {tabel }} 1,84$, ini menunjukkan kemampuan awal siswa dalam pretest pada kedua kelompok sampel adalah sama. Hasil uji hipotesis dua pihak menggunakan uji $\mathrm{t}$ dapat ditunjukkan pada Tabel 4.

Tabel 4 Ringkasan Uji Hipotesis Dua Pihak (Pretest)

\begin{tabular}{|l|l|l|l|}
\hline Data & $\begin{array}{l}\text { Rata- } \\
\text { Rata }\end{array}$ & $\mathbf{t}_{\text {hitung }}$ & $\mathbf{t}_{\text {tabel }}$ \\
\hline Eksperimen & 31,5 & 0,44 & 1,84 \\
\cline { 1 - 2 } Kontrol & 30,3 & & \\
\hline $\begin{array}{l}\text { Kesimpulan: } \\
\text { Kemampuan awal siswa pada kedua } \\
\text { kelas sama }\end{array}$ \\
\hline
\end{tabular}

Hasil uji hipotesis satu pihak menggunakan uji $\mathrm{t}$ diperoleh bahwa $\mathrm{t}_{\text {hitung }}$ 6,5 dan $\mathrm{t}_{\text {tabel }} 1,59$, dapat disimpulkan bahwa ada pengaruh yang signifikan dengan menggunakan model pembelajaran scientific inquiry dibandingkan model pembelajaran konvensional terhadap hasil belajar siswa pada materi fluida dinamis. Hasil uji hipotesis satu pihak menggunakan uji t dapat ditunjukkan pada Tabel 5. 
Tabel 5 Ringkasan Uji Hipotesis Satu Pihak (Post-test)

\begin{tabular}{|l|l|l|l|}
\hline Data & $\begin{array}{l}\text { Rata- } \\
\text { Rata }\end{array}$ & $\mathbf{t}_{\text {hitung }}$ & $\mathbf{t}_{\text {tabel }}$ \\
\hline Eksperimen & 76,3 & 6,5 & 1,59 \\
\cline { 1 - 2 } Kontrol & 63 & & \\
\hline \begin{tabular}{l} 
Kesimpulan: \\
Ada pengaruh model scientific inquiry \\
\hline
\end{tabular}
\end{tabular}

Penilaian aktivitas belajar siswa dilakukan pada kedua kelas sampel yaitu kelas eksperimen dengan model scientific inquiry dan kelas kontrol dengan model konvensional. Aktivitas belajar siswa pada kelas eksperimen tiap pertemuan mengalami peningkatan, yaitu pada pertemuan I dengan rata-rata $69,2 \%$, pada pertemuan II dengan rata-rata $81,8 \%$ dan pada pertemuan III dengan rata-rata 90,6\%. Aktivitas belajar siswa pada kelas kontrol juga mengalami peningkatan tiap pertemuannya, yaitu pada pertemuan I dengan rata-rata $41,8 \%$, pada pertemuan II dengan rata-rata $47,3 \%$ dan pada pertemuan III dengan rata-rata $56,5 \%$. Dapat disimpulkan bahwa rata-rata aktivitas belajar kelas eksperimen $80,53 \%$ termasuk kategori aktif dan rata-rata aktivitas belajar kelas kontrol 48,53\% termasuk kategori kurang aktif. Hasil aktivitas belajar siswa ditunjukkan pada Gambar 3.

Gambar 3 Diagram Batang Aktivitas Belajar Kelas Eksperimen dan Kelas Kontrol

\section{Pembahasan}

Hasil pretest kelas eksperimen memperoleh nilai rata-rata 31,5 dan nilai rata-rata kelas kontrol adalah 30,3. Hasil tersebut menyatakan bahwa kemampuan awal siswa pada kelas eksperimen sama dengan kemampuan awal pada kelas kontrol sebelum diberi perlakuan.

Hasil posttest diperoleh bahwa ratarata nilai hasil belajar siswa pada kelas ekperimen yang menggunakan model pembelajaran scientific inquiry adalah 76,3, sedangkan pada kelas kontrol yang menggunakan model pembelajaran konvensional diperoleh rata-rata nilai hasil belajar siswa adalah 63. Hasil rata-rata posttest kelas ekperimen menunjukkan kriteria penilaian tuntas yaitu dari 30 siswa terdapat 20 siswa atau $66,6 \%$ yang mendapat nilai sesuai KKM yaitu 75, sedangkan 10 siswa atau 33,3\% tidak mendapat nilai sesuai KKM. Hasil rata-rata posttest kelas kontrol menunjukkan kriteria penilaian tidak tuntas yaitu 4 dari 30 siswa atau $13,33 \%$ mendapatkan nilai sesuai KKM sedangkan 26 siswa atau 86,66\% mendapatkan nilai tidak sesuai KKM. Berdasarkan hasil observasi awal peneliti pada latar belakang diperoleh data bahwa $65 \%$ siswa tidak mampu mencapai nilai sesuai KKM. Pada hasil penelitian ini menunjukkan $33,3 \%$ siswa tidak mampu mencapai nilai sesuai KKM. Ini menunjukkan terjadi peningkatan sebesar $31,7 \%$ untuk jumlah siswa yang mendapat nilai sesuai KKM dengan menggunakan model pembelajaran scientific inquiry.

Hasil tersebut sesuai dengan penelitian yang dilakukan oleh Hussain, dkk (2011) dimana dengan menggunakan pembelajaran konvensional diperoleh nilai rata-rata sebesar 31,2667 dan dengan menggunakan pembelajaran scientific inquiry diperoleh nilai rata-rata sebesar 37,6556. Dari penelitian tersebut disimpulkan bahwa ada pengaruh yang signifikan terhadap prestasi belajar siswa yang diajarkan dengan model pembelajaran scientific inquiry dengan metode inkuiri terbimbing, terarah dan kombinasi daripada pembelajaran konvensional. 
Pada penilaian aktivitas belajar kelas eksperimen dilihat dari kegiatan belajar yang dilakukan yaitu dari sintaks model pembelajaran scientific inquiry. Penilaian aktivitas belajar pada kelas kontrol dilihat dari kegiatan belajar yang dilakukan yaitu dari fase model pembelajaran konvensional. Hasil pengamatan terhadap aktivitas belajar siswa yang dilakukan setiap pertemuan yaitu sebanyak tiga kali pertemuan pada kedua kelas sampel. Rata-rata aktivitas belajar pada kelas eksperimen adalah $80,53 \%$ termasuk kategori aktif dan rata-rata aktivitas belajar pada kelas kontrol adalah 48,53\% termasuk kategori kurang aktif. Hasil peningkatan aktivitas belajar dengan menggunakan model scientific inquiry sesuai dengan penelitian Rahayu. dkk., (2015) dengan judul yang menunjukkan bahwa terjadi peningkatan pada hasil belajar kognitif sebesar 30,41\% dan peningkatan pada hasil belajar afektif sebesar $23,11 \%$. Selain itu, pada penelitian Sihotang (2014) yang menyatakan bahwa model pembelajaran scientific inquiry dapat meningkatkan hasil belajar dan sikap ilmiah yang tinggi pada siswa.

Model scientific inquiry ini berdasarkan pada pendekatan saintific yang meliputi mengamati, menanya, mengumpulkan informasi, mengolah informasi dan mengkomunikasikan. Pada aktivitas belajar kelas eksperimen, berdasarkan pendekatan saintific yang lebih dominan yaitu pada kegiatan mengumpulkan informasi dan mengkomunikasikan . Pada kegiatan tersebut siswa sangat berperan aktif dalam menemukan sendiri beberapa konsep dari materi tersebut. Ini menunjukkan bahwa pendekatan scientific dapat meningkatan pada aktivitas belajar siswa. Hal ini sesuai dengan penelitian Indah dan Utiya (2014) yang menyatakan bahwa aktivitas siswa pada pembelajaran didominasi oleh aktivitas mengkomunikasikan yaitu pada pertemuan I sebesar 32\% dan pertemuan II sebesar $23 \%$.
Model scientific inquiry dapat dipandang satu set keterampilan yang harus dipelajari oleh siswa dan dikombinasikan dengan kinerja penelidikan ilmiah. Scientific inquiry juga dapat dilihat sebagai hasil belajar kognitif siswa yang akan dicapai. Hal tersebut sejalan dengan penelitian yang dilakukan oleh Lederman, dkk (2013) yang menyimpulkan bahwa scientific inquiry salah satu model pembelajaran untuk mengembangkan pengetahuan dan sikap ilmiah siswa.

Penggunaan model scientific inquiry dapat meningkatkan hasil belajar siswa, namun ada beberapa kendala yang dihadapi peneliti seperti (1) pada saat melakukan praktikum masih banyak siswa yang bertanya mengenai prosedur kerja selama praktikum, sementara petunjuk kerja sudah dijelaskan di lembar kerja siswa (LKS), ini dikarenakan kurangnya minat membaca siswa dalam menemukan sendiri sehingga membutuhkan waktu yang lama dalam menjelaskan berulang-ulang prosedur kerja pada lembar kerja siswa (LKS) tersebut, (2) siswa masih bingung dengan kegiatan belajar dari model yang digunakan peneliti seperti untuk menentukan rumusan masalah dan hipotesis masih sebagian siswa yang dapat menentukannya, ini dikarenakan pada hal ini siswa dituntut untuk berpikir tinggi sehingga hanya sebagian siswa yang dapat mengikutinya, (3) beberapa siswa masih kurang kondusif selama pembelajaran, dan (4) manajemen kelas, dimana peneliti masih kurang memperhatikan waktu sehingga ada beberapa penjelasan dan materi yang belum dijelaskan.

Kendala yang dihadapi oleh peneliti diharapkan kepada peneliti selanjutnya agar lebih baik dalam mengelola kelas agar situasi kelas lebih kondusif selama proses pembelajaran berlangsung. Bagi guru diharapkan dapat menggunakan model scientific inquiry sebagai salah satu model pembelajaran untuk meningkatkan hasil belajar siswa.

\section{KESIMPULAN}


Berdasarkan hasil penelitian yang diperoleh dari hasil analisa data dan pengujian hipotesis maka dapat disimpulkan bahwa ada pengaruh dari model pembelajaran scientific inquiry terhadap hasil belajar siswa pada materi fluida dinamis kelas XI semester II di SMA Negeri 1 Pancurbatu tahun pelajaran 2015/2016 dengan hasil uji hipotesis satu pihak $\mathrm{t}_{\text {hitung }}=6,5>\mathrm{t}_{\text {tabel }}$.

\section{DAFTAR PUSTAKA}

Badan Standar Nasional, (2006), Standar Kompetensi Lulusan SMA.

Hussain, A., Muhammad A., dan Azra S., (2011), Physics Teaching Methods: Scientific Inquiry VS Traditional Lecture, International Journal of Humanities and Social Science, 1(19), Page269-276, USA.

Indah, Y.A.S., dan Utiya A., (2014), Penerapan Model Pembelajaran Inkuiri Terbimbing dengan Pendekatan Saintifik (Scientific Approach) Pada Materi Pokok Larutan Elektrolit dan Non Elektrolit Kelas X MIA 5 SMAN 3 Surabaya, Unesa Journal of Chemical Education, Universitas Negeri Surabaya.

Joyce, B., Weil M., dan Calhoun E., (2009), Models Of Teaching: Model-Model Pengajaran, Pustaka Pelajar, Yogyakarta.

Lederman, N.G., Judith S.L., dan Allison A., (2013), Nature of Science and Scientific Inquiry as Contexts for the Learning of Science and Achievement of Scientific Literacy, International Journal of Education in Mathematics Science and Technology, 1(3), Page 138-147, Illinois Institute Of Technology.

Rahayu, S.F., Sriyono., dan Nurhidayati, (2015), Efektivitas Model Pembelajaran Scientific Inquiry Berbasis Pictorial Riddle dalam Meningkatkan Hasil Belajar Fisika Siswa Kelas VIII SMPN 1 Adimulyo Kebumen, Jurnal Radiasi Prodi
Pendidikan Fisika, Universitas Muhammadiyah Purworejo.

Sihotang, D.C.N., (2014), Analisis Model Pembelajaran Scientific Inquiry dan Sikap Ilmiah Terhadap Hasil Belajar Siswa pada Materi Listrik Dinamis Kelas X, Junal Pendidikan Fisika, Universitas Negeri Medan.

Sudjana, (2001), Metoda Statistika, Tarsito, Bandung. 